\title{
LAS CIUDADES MUSULMANAS Y SU URBANIZACION
}

$\mathrm{H}$ ASTA comienzos del.siglo XX la mayoría de las ciudades y villas españolas conservaron su estructura medieval. En el XVI abriéronse plazas y ensancháronse calles en algunas de ellas, al mismo tiempo que se levantaban, en esa centuria y en las siguientes, palacios y edificios monumentales. Durante la ocupación francesa de principios del siglo XIX fueron demolidos no pocos conventos, cuyos solares pasaron a ser plazas. Pero ni estas ni otras modificaciones lograron alterar, al través de cuatrocientos cincuenta años, las líneas generales del antiguo trazado de nuestras agrupaciones urbanas. I a vida variaba en ellas durante ese tiempo con ritmo lentísimo y el cuadro urbano en el que tenía lugar modificábase también lenta e insensiblemente, sin cambios bruscos. La ciudad iba adaptándose cotidianamente y de una manera natural a la existencia de sus pobladores.

Pero ahora esa doble transformación no se verifica al mismo ritmo. Los habitantes de la urbe aumentan con rapidez extraordinaria y su vida de relación sufre, por circunstancias muy diversas, modificaciones bruscas y profundas, mientras la ciudad, más rígida y permanente, como producto de la industria humana, varía con gran lentitud. Las gentes se siente incómodas en el estrecho y anacrónico escenario de sus actividades, y se difunde entre ellas el deseo natural de adaptar la ciudad al aumento del número de sus pobladores y a las nuevas formas y condiciones de vida. Fsta adaptación será forzoso realizarla bruscamente y en brevísimo plazo, confiándola a unos técnicos. Si éstos se equivocan, la vida ciudadana quedará afectada por el error durante un dilatado número de años.

Para el que va a dirigir la transformación de una ciudad es de capital importancia dominar la técnica moderna relacionada con ese problema, pero no debe olvidar otros aspectos, de índole más abstracta, y por ello más difíciles de aprehender. El medio físico de una aglo- 
meración urbana está intimamente unido a otros dos: el social y el moral de los sentimientos y de las ideas. En sí mismas las formas tienen gran importancia, pero las condiciona siempre el espíritu, cuyas raíces se hunden en el vasto reino del pretérito. El presente sólo puede explicarse a través del pasado, una de cuyas funciones más útiles es la de servir de brújula al porvenir.

Una ciudad vieja, como lo son la mayoría de las españolas, es un cuerpo vivo, modelado por varios siglos y multitud de generaciones. Si se la reforma con ignorancia o desprecio de su tradición, haciendo tabla rasa de su pasado y de sus recuerdos monumientales, el resultado será desastroso. Se habrá roto la continuidad secular que debe haber en toda obra humana bien lograda y, desprovista de raíces, será una creación artificial sin alma y sin belleza.

El técnico encargado de una reforma urbana deberá, pues, conocer cómo se ha ido formando la ciudad que va a modificar y tener conciencia'de que su obra no debe ser más que una fase de un desarrollo sin solución de continuidad. Pasado, presente y futuro de la urbe son momentos de un mismo proceso histórico y, el último tiempo, consecuencia obligada'de los otros dos.

El ideal que debe presidir la transformación de nuestras viejas ciudades, impuesta por su rápido crecimiento y por los cambios radicales de la vida moderna, será el de mantenerse igualmente alejados de un mezquino espíritu arqueológico que pretenda sacrificar necesidades vitales a la conservación de formas muertas, y de una admiración excesiva por reglas y soluciones extrañas, casi siempre de difícil trasplante e imposible aclimatación en un ambiente tan vigorosamente original como es el hispánico.

Para que el urbanista pueda, pues, emprender acertadamente su labor, se impone, cada día que pasa con mayor apremio, el estudio, apenas iniciado, de la evolución urbana de las ciudades españolas.

Pero ese estudio tiene más vasto alcance. Ignorando la historia de nuestras urbes no lograremos un conocimiento íntegro y cabal de la vida española, de la de hoy ý de la del pasado, ya que ésta ayuda a comprender a la primera. La vida de todo pueblo, ha dicho uno de los más sutiles escritores contemporáneos, está circunscrita en el tiempo y en el espacio, es decir, en la historia y en el paisaje. Acostumbramos recordar los hechos históricos con absoluta independencia de los lugares en que se realizaron, sin evocar su ambiente y sus paisajes geográfico o monumental, es decir, su escenario. $\mathrm{Y}$ las ciudades han sido siempre los grandes escenarios históricos, no sólo de la cró- 
nica política y de los hechos espectaculares, sino también de esa otra historia que va creando a través de los siglos la labor lenta, afanosa y sin resonancia de millares y millares de seres anónimos.

El proceso histórico de nuestra urbanización presenta el original dualismo de toda la vida española durante la Edad Media, latente en el Renacimiento y cuya impronta se acusa aún en el momento presente. Consiste, excusado es decirlo, en el contacto de las dos grandes corrientes de civilización, la oriental y la occidental, que han dado lugar a una riqueza y variedad de formas mayor en el nuestro que en la mayoría de los otros pueblos.

Las páginas siguientes forman parte de un estudio sobre la historia de la urbanización de las ciudades españolas de influencia oriental, es decir, sobre las hispanomusulmanas. Para realizarlo no tenemos la gran cantidad de documentos que se conservan con datos sobre otras ciudades de un pasado bastante más lejano, como, por ejemplo, la Roma imperial, y que han permitido últimamente a Carcopino trazar un cuadro completo y animado de la gran urbe en los primeros siglos de nuestra era. La penuria de datos y documentos islámicos habrá que suplirla acudiendo a las épocas posteriores, en primer lugar a las que siguen inmediatamente a la reconquista cristiana, y a las huellas, cada día que pasa más escasas, que el fluir del tiempo ha dejado en el cuadro urbano. Las ciudades del norte de Africa, reflejo muchas de ellas de las hispanomusulmanas, también pueden ayudarncis a evocar lo que éstas fueron.

En nuestras ciudades de pasado islámico, la catedral y las antiguas iglesias deben su emplazamiento a que en el mismo solar estuvieron antes la mezquita mayor y otras secundarias; gran parte de las calles actuales conservan su trazado medieval, y las rondas y paseos que circundan la población siguen las mismas líneas de su antigua cerca. Si el sereno con su farol y chuzo pas a aún las calles vigiiando nuestro sueño, débese a que en la época islámica había también un guarda nocturno encargado de velar por la seguridad de los vecinos. $Y$ si de las huellas materiales pasamos a las mâs sutiles conservadas en la vida y en el espíritu de sus habitantes, comprobaremos también que el pasado informa y está presente en todos los momentos de la vida actual. "¿Cómo dicen que no hay monumentos romanos en Inglaterra? Todos nosotros lo somos", ha escrito Chesterton. Aún hoy, como hace siete siglos, constituye la suprema belleza 
femenina para los andaluces el contraste entre la cadera pingüe y el talle frágil, según frase de García Gómez. De muchos sevillanos se podría repetir actualmente lo que escribía Al-Saqundi en el siglo XIII: "Son las gentes más ligeras de cascos, más espontáneas para el chiste y más dadas a la burla..., y de tal suerte están 'habituadas a esto y lo tienen por hábito, que entre ellos es considerado odioso y cargante el que no se dedica a tales cosas y no da y acepta esta clase df bromas".

Disposición del sistema viario.

Una de las características que diferenciaban más profundamente a las ciudades musulmanas de la Edad Media, lo mismo a las orientales que a las del Norte de Africa y de nuestra Península, de las de Occidente, era el trazado de sus calles. Casi todas las de las últimas

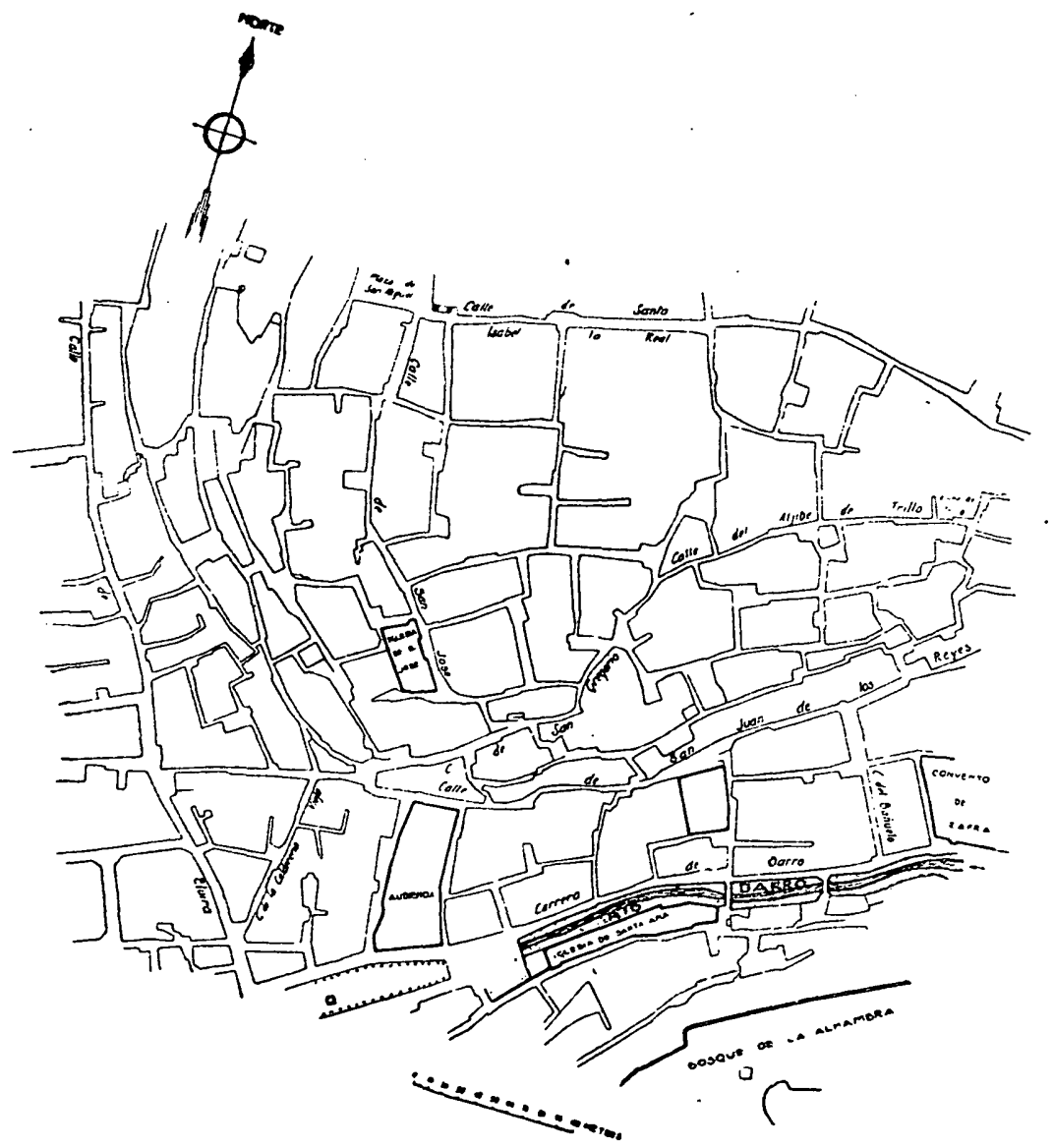


eran vías de tránsito, en comunicación con otras por sus dos extremos, sin solución de continuidad; servían, a la vez, para encauzar la circulación general urbana y de acceso a las viviendas que las bordeaban.

Las ciudades islámicas poseían también unas cuantas vías transversales o radiales que comunicaban las puertas opuestas del recinto murado de la medina, prolongadas a través de los arrabales inmediatos. Pero desde ellas arrancaban calles estrechas y tortuosas de las que partían a su vez gran número de callejones sin salida, que se ramificaban laberínticamente como las venas en el cuerpo humano. Este mismo trazado viario, simplificado y reducido a menores proporciones, se repetía en cada uno de los barrios y arrabales de alguna extensión. El plano de Sevilla de 1771, el de Málaga veinte

CORDOBA.-Plano de los alrededores de la Mezquita mayor en 1811, según el plano de Karvinki y Rillo.

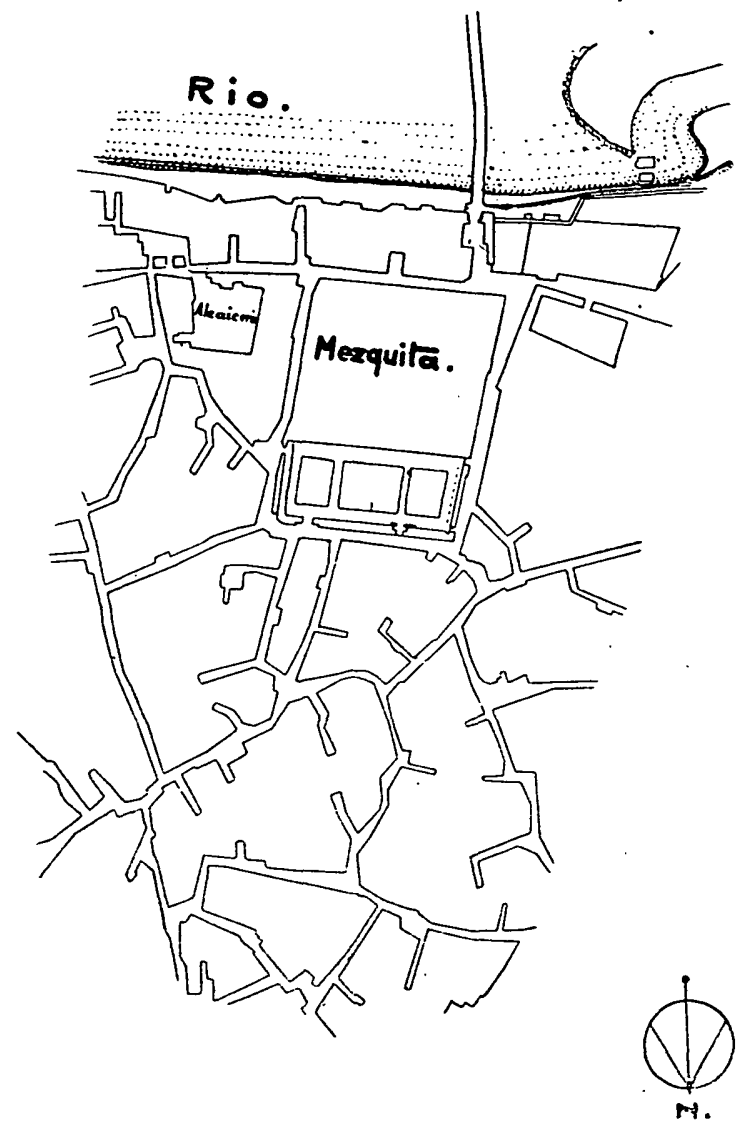

años posterior, el de Granada de 1796 y el de Córdoba de 1811 muestran claramente tal disposición, de la que aun quedan restos en los 
barrios menos renovados de esas ciudades, como son el inmediato al alcézàr de Sevilla, el que en Granada se extiende por la pendiente del Darro opuesta a la de la Alhambra, y el que rodea la mezquita cordobesa. El acentuado relieve del solar toledano y los profundos sótanos y cimientos de muchos de sus edificios obligaron a las calles a seguir el mismo camino durante siglos, razón por la que también se conservan en esa ciudad crecido número de callejones sin salida.

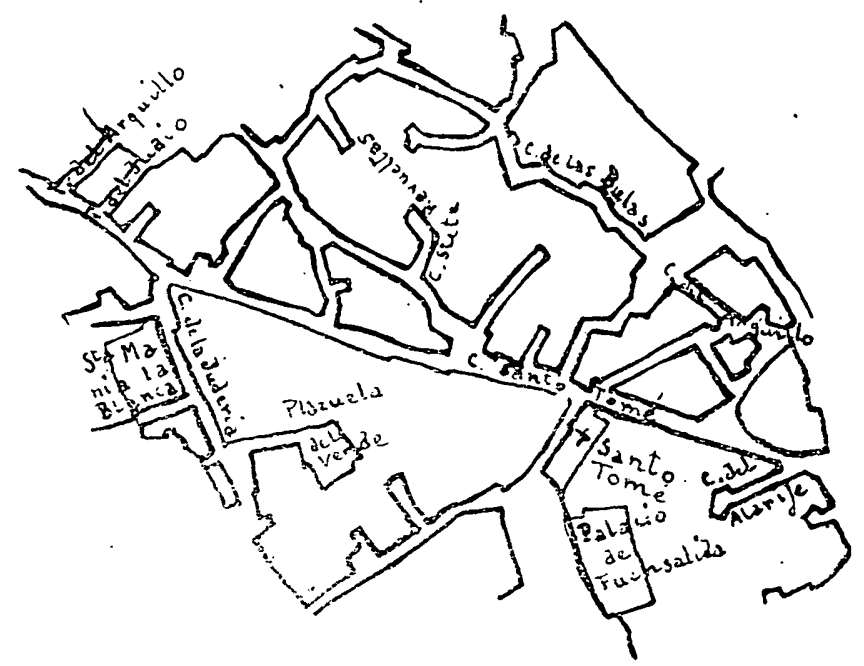

TOLEDO.-Plano de uno de los sectores urbanos, comprendiendo parte de la antigua judería.

Antiguos documentos referentes a fincas urbanas, como los mozárabes toledanos de los siglos XII y XIII, mencionan con frecuencia calles, callejones y adarves sin salida.

Aunque se trata de un reducido barrio, de carácter probablemente militar, es buen ejemplo de ese trazado el de la plaza de Armas de la alcazaba de la Alhambra, los cimientos de cuyas viviendas salieron a luz en excavaciones realizadas hace algunos años. En las que dirigí en la etapa de 1923-1936 en el Secano del mismo recinto granadino aparecieron también ruinas de pequeñas casas cuyas puertas de ingreso se abrían, como en las de la alcazaba, en el fondo de estrechos callejones.

Un forastero extraviado en el siglo $\mathrm{X}_{\mathrm{\gamma}} \mathrm{V}$ en una ciudad española de abolengo occidental, Valladolid, Burgos o Barcelona, por ejemplo, hubiera podido, como en las modernas, continuar indefinidamente calle tras calle, dando vueltas por ella. El que no conoce bien Toledo 64 y gusta de recorrer al azar sus pintorescas callejuelas, es frecuente 
que tenga que desandar el eamino al llegar al final de alguna sin salida, desierta y silenciosa, entre cuyos guijarros crece la hierba.

No heredaron esta disposición las ciudades islámicas de las romanas. Véanse, por ejemplo, los planos de las itálicas de Pompeya y Ostia, de las africanas de Timgad y Numidia (Djemila), de las hispánicas de Azaila y Numancia. Todas ellas tienen trazados relativamente regulares, con calles que se comunican con otras por sus dos cabos. Esa disposición llegó a Occidente desde el otro extremo del Mediterráneo, tal vez a través de Siria, donde los árabes habitaron por primera vez centros urbanos de alguna importancia. Y a Siria pudo trasmitirse desde las pequeñas ciudades del Yemen, en el Sur de Arabia, de las que salieron gran número de comerciantes y artesanos para establecerse en el Irak y Andalucía. Sería interesante para la historia de la evolución urbana llegar a conocer detalladamente el proceso mediante el cual se fué transformando el trazado viario de una gran ciudad romana, como era Damasco, hasta convertirse en el oriental que en gran parte conserva. Con los omeyas debió pasar a España esa disposición urbana y desde nuestro país trasmitirse más tarde al Africa del Norte.

$\mathrm{Ni}$ en Oriente ni en Occidente sintieron los musulmanes preocupación alguna de orden municipal respecto al trazado y ancho de las calles y a los edificios que las bordeaban. La ley islámica tampoco dispone nada acerca de la reglamentación de las construcciones y de su emplazamiento. Al mubtasik-el almotácen-, que perduró en algunas de nuestras ciudades hasta bien entrado el siglo XVI, funcionario delegado del cadí, encargado en las grandes villas musulmanas de velar por las costumbres públicas y por la probidad de comerciantes y.artesanos, comprobar sus pesas y medidas y castigar los fraudes, hacer cumplir su deber a los funcionarios y mantener el orden y la limpieza en los lugares públicos, tan sólo se le exigía que obligase a los propietarios de las casas ruinosas a demolerlas para evitar los accidentes de que pudieran ser víctimas los transeúntes.

En los dos tratados españoles que se conocen de bisba-vademécum o manual del perfecto almotácen-, escritos en los siglos XI al XII en Sevilla y Málaga, en los que se fijan muy detalladamente las obligaciones de ese funcionario, tan sólo se alude, respecto a la edificación, al derribo de casas ruinosas y de otras indebidamente levantadas en los cementerios, así como a la construcción de sus muros y a las condiciones a que han de satisfacer los materiales empleados en ellas.

La evolución de la ciudad en la sociedad islámica era, pues, fruto 
de la iniciativa privada. Tan sólo la de algún personaje poderoso podía conseguir modificaciones de importancia en la disposición urbana. Tal ocurrió, por ejemplo, en Sevilla en 1171-72, cuando el soberano almohade Abu Yaqub Yusuf mandó derribar varias casas que había en la alcazaba para construir en su solar una nueva mezquita mayor, por resultar insuficiente la utilizada para ese destino.

\section{Las calles principales.}

Las escasas calles transversales o radiales enlazaban las entradas más concurridas de la ciudad, encauzando el tráfico a través de ella. En el 'plano actual de Córdoba se reconoce aún el trazado de las vías que, atravesando la medina, unían las puertas opuestas: la principal, que va de Norte a Sur, desde la del Osario (bab Luyun), por la actual calle de Jesús y María, para bajar por la cuesta de Pedregosa y, tras su paso entre el alcázar y la Mezquita mayor, alcanzar la puerta del Puente (bab al-Qantara). Esta gran calle se llamaba al-mabaggaal-uzma. Otra, cruzando también la ciudad, iba de Oriente a Poniente, desde la puerta de Gallegos ( $b a b$ Amir) a la de Hierro.(bab al-Hadid), por las calles que hoy llevan los nombres de Concepción, Gondomar y Alfonso XIII, a Zapatería.

Como un resto del trazado viario musulmán de Sevilla puede considerarse a la larga calle, probablemente la bara mayur, en la que Abu Yaqub Yusuf mandó contruir a fines del siglo XII un depósito para el agua conducida por los Caños de Carmona, que, según el historiador Péraza, partía Sevilla en el siglo XVI, comenzando en la puerta del Arenal para terminar en la de Macarena ( $b a b \mathrm{Ma}$ karana).

La Granada musulmana tenía dos calles principales: la que unía la puerta de Elvira (bab Ilbira) con el centro de la ciudad y que proseguía después, con algún quebranto, hasta la puerta de Bibataubin (bab at-tawwahin), y la que, arrancando de la puerta de Guadix, seguía bordeando el curso del Darro. La primera iba por la calle de Elvira y; déspués de cruzar la otra, seguía por lạs de San Matías, llamada entonces Axibin, y por la de Bibataubin.

Todavía se conserva el trazado de la vía principal que atravesaba Málaga de Levante a Poniente.

Dentro de cada barrio de alguna importancia o arrabal había también su arteria principal. En el poblado o barrio exterior de la Xarea, en Valencia, cita el "Repartimiento", poco después de la Reconquista, la calle mayor. de ese nombre. 
Las numerosas referencias literarias a la mayor o menor anchura de las calles, si, como es to frecuente, no concretan su medida, son de poca utilidad, pues ignoramos el término de comparación utilizado para calificarlas. De las de Zaragoza dice Idrisi a mediados del siglo XII que eran anchas. A comienzos del XVI, en 1526, cuando aún el trazado de las calles de la Sevilla musulmana no había sufrido grandes modificaciones, las describe Navajero como anchas y hermosas; tal vez el clima húmedo y caluroso contribuyera a que fuesen menos angostas que en otras poblaciones. Pero había barrios en Sevilla, como el situado junto al Alcázar, que hasta el siglo XIX conservó callejones estrechísimos, entrie ellos el del Ataúd, capaz sólo para el paso de una persona.

El notario mallorquín Pedro Llitrá, que entró en Málaga con İos Reyes Católicos cuando su conquista en 1487, dice que tan sólo tenía esa ciudad dos o tres calles razonablemente espaciosas.

La calle de Elvira de Granada, con nombre que se mantiene desde el siglo XI, y las líneas generales de cuyo trazado no deben haber variado mucho desde el $\mathrm{XV}$, puede dar idea de las dimensiones de las vías más importantes de las ciudades hispanomusulmanas. De principal y bastante ancha y larga la califica el citado embajador veneciano Andrea Navajero en 1526; durante los cinco siglos transcurridos desde entonces no se han disminuído sus angosturas e irregularidades, a pesar de que hasta principios del actual continuó siendo la más importante vía de acceso al centro de la ciudad. La otra calle que cruzaba Granada de Oriente a Poniente, siguiendo el cauce del Darro, aun era más estrecha y tortuosa, como puede juzgarse por antiguos planos y alguna fotografía anteriores al abovedamiento del río; aún hoy, acrecentada y con el nombre de los Reyes Católicos; parece estrecha.

Accidentalmente debía haber en algunas de las calles más holgadas, o en lugares en los que se ensanchaban para formar como pequeñas plazas, algún árbol. A una palmera alude en el siglo XIII el Cazvini, gran relator de fantásticas leyendas, como existente en una calle de Sevilla. Tan inclinada estaba - dice-, que dificultaba el tránsito y se pensó en cortarla para desembarazar la vía. Quejóse la palmera a Mahoma, y, éste, al acariciarla con su bendita mano, logró enderezarla. Desde entonces las gentes tuvieron en gran veneración aquel lugar.

La mayoría de las calles, aún las de barrios excéntricos, como ocurría en el Albaicín de Granada, tenían un pequeño cauce en su parte central para recoger las aguas de lluvia, en el que vertían de 
noche las sucias los vecinos de las casas desprovistas de conducciones subterráneas.

\section{Calles secundarias y callejones sin salida.}

Calles secundarias y callejones sin salida eran angostos, oscuros y tortuosos. Queda recuerdo escrito de haber sido ásí los de varias ciudades hispanomusulmanas, y aún hoy pregonan su estrechura y desigualdad algunos que permanecen en bastantes de ellas.

Las Ordenanzas de Granada de la primera mitad del siglo XVI se refieren a "la estrechura de calles y plazas". Las calles de su Albaicín las describe el alemán Jerónimo Münzer en 1494 como "tan sumamente estrechas, que en muchas de ellas por la parte de arriba se tocan los tejados de las casas fronteras, y por la de abajo no podrían pasar dos asnos que fueran en direcciones contrarias; las más anchas no miden más de cuatro a cinco codos". Y Luis del Mármol, casi un siglo después, afirma que eran las calles granadinas "tan angostas que de una a otra ventana se alcanzaba con el brazo, y había muchos barrios donde no podían pasar los hombres a caballo con las lanzas en las manos, y tenían (los moros) las casas horadadas de una a otra parte para poderlas sacar, y esto dicen los moriscos que se hacía de industria para mayor fortaleza de la ciudad".

El mallorquín Llitrá refiere que en 1847 la ciudad de Málaga no tenía "más que dos o tres calles razonablemente espaciosas; las demás son tristes y tan estrechas, que en algunas una caballería algo lozana apenas podría rebullirse". De lo tortuoso de estas vías dice elocuentemente el nombre de las "Doce revueltas" con el que se conocían unas callejuelas malagueñas, a las que se ingresaba por un arco, pasado un año de su conquista por los Reyes Católicos, y aun se llama de "Siete revueltas" un callejón inmediato a la iglesia de Santiago de Málaga, en parte desaparecido al hacer la calle de Larios. Con el mismo nombre existían calles en Sevilla y Jerez en la segunda mitad del siglo $\mathrm{XV}$, y aún lo conserva un callejón toledano sin salida, restos sin duda de su pasado islámico.

El mismo origen, según se dijo, tiene gran parte del trazado urbano de Toledo. El doctor Piza escribía a comienzos del siglo XVIS cargando la culpa a los moros de haber quedado algunas calles tole danas "angostas, torcidas y con veinte revueltas", por lo que To. ledo no cobró nunca "del todo el lustre y hermosura de calles que los romanos y los godos dejaron en ella". Las Ordenanzas de esta ciuda.d. recopiladas en el siglo $X V I$, pero de tradición anterior, obligaban \& no volar las alas de los tejados de las calles, es decir, los aleros; 
más del tercio de la anchura de éstas, dejando "el otro tercio en medio, para ayre, e por do entre la lumbre, e para do caygan las aguas", lo que supone un ancho de calle "ideal", menor de dos metros, ya que el vuelo de cada tejado no alcanzaría más de sesenta centímetros.

En el siglo XVII, época de gran bienestar y riqueza en Murcia, hubo que ensanchar bastantes de sus calles, algunas de las cuales medían sólo cinco palmos (1,04 metros). Abundaban las desprovistas de salida.

El deán Martínez Mazas, uno de esos españoles del reinado de Carlos III apasionados por la noble tarea de restaurar su patria, escribía de las casas y calles de Jaén que, "por más que en quinientos cuarenta y cinco años que han pasado después de la conquista se habrán renovado mucho, siempre manifiestan que fueron edificadas por los moros. Las calles son angostas y torcidas; las casas, sin arreglo ni igualdad".

En el plano de Sevilla de 1771, debido a la iniciativa del asistente don Pablo de Olavide-otro hombre que honra a nuestro siglo XVIII-, se ven numerosos callejones que, por carecer de ella, se nombran "sin salida". Antes de mediar el siglo pasado habían desaparecido de la metrópoli del Guadalquivir muchas calles de la parte SE. del recinto murado, como la citada del Ataúd, que sólo permitía el paso de una persona.

El frecuente y caprichoso cambio de anchura y dirección de las calles daba lugar a numerosas rinconadas que hacían oficio de pequeñas plazoletas.

Excusado es decir que todos los transportes en el interior del área urbana se realizaban en mulos o borricos, como hasta hoy en el Albaicín y en otros barrios altos de Granada y de otras ciudades andaluzas. Esto se reflejaba en las dimensiones de algunas partes de los edificios, al no ser posible transportar más que materiales de reducido peso y magnitud, así como en el mucho tiempo empleado en su construcción.

Calles encubiertas, arquillos, saledizos y ajimeces.

Calles y callejones aparecían cortados frecuentemente por cobertizos y pasos que unían las plantas altas de las casas fronteras situadas a un lado y otro de la calle, disposición de la que aun se conservan restos en Toledo y en varias villas andaluzas, aragonesas y valencianas. La calle quedaba así parcialmente "encubierta". Continuaron construyéndose estos pasadizos sobre las calles aun después de la Reconquista. Las Ordenanzas de Toledo disponen que los que cons- 
truyan "sobrados que atrauiessen las calles, a que dizen encubiertas", deben hacerlos de altura suficiente para que pueda pasar bajo ellos "el cauallero con sus armas, e que non le embargue".

Era también frecuente que la calle estuviese cortada por un muro transversal con un pequeño arco y puerta que se cerraba por las noches, disposición que facilitaba el aislamiento y defensa de los vecinos. Cuenta Ibn Said que había en Córdoba en el siglo XII, empleados municipales armados, llamados darrab, encargados de cerrar por las noches las puertas de las calles o barrios, como en Fez hasta hace poco tiempo. Cada calle, añade el citado historiador, según un relato trasmitido por Maqqari, tenía un vigilante nocturno, provisto de un farol y acompañado por un perro que ladraba al menor ruido insólito, origen de institución tan típicamente española como es la del sereno. Se ven aún de esos arquillos en no pocas de nuestras villas y en ciudades como Sevilla el nombre de varias calles registraba su existencia hasta el siglo pasado. "Sin arreglo ni igualdad" juzgaba el aspecto exterior de las casas de Jaén, heredado de las musulmanas, el deán Martínez Mazas hace algo más de ciento cincuenta años. En una época de estética urbana de no tan clásica regularidad como el siglo XVIII, Pedro Llitrá escribía que "las fachadas de las casas-de Málaga-son... muy tristes y de muy mal aspecto"; bien es verdad que el notario mallorquín conocería sin duda Valencia, Barcelona y otras ciudades levantinas de las de mejor caserío urbano por entonces.

Pero esas calles tan estrechas en su trazado lo eran aún más en elevación, por el frecuente avance sobre ellas de los pisos altos de las casas, volados por medio de tornapuntas o jabalcones, y por los salientes aleros, que las ensombrecían. Hasta el siglo pasado se conservó en Granada algún ejemplar de planta alta volada sobre jabaícones, disposición aún frecuente en las ciudades orientales y norteafricanas.

Saledizos también eran los ajimeces, balcones volados de madera cerrados por celosías, a los que se asomaban las mujeres: para ver sin ser vistas (1) ; conservan su recuerdo los que aun existen en algunos conventos de monjas de nuestras viejas ciudades. Los había en Málaga y en Granada cuando fueron conquistadas por los Reyes Católicos, y aun se construían a principios del siglo XVI en Córdoba, Sevilla y Toledo, según testimonios que se aducen más adelante.

Aparte de estos saledizos de las fachadas de algunas casas, apenas si la d€ৎnudez de los muros exteriores quedaría interrumpida por escasos y reducidos huecos: "Las de los moros, de ordinario-escri-

(1) Desde la época romántica se viene dando el nombre de ajimeces, equivocadamente, a las ventanas gemeias. 
be Cervantes-más eran agujeros que ventanas, y aún éstas se cubrían con celosías muy espesas y apretadas." Algunas ventanas tenían rejas; cuenta un cronista que Fajr al-dawla, hijo del célebre Almotamid, rey de taifas de Sevilla, quedó un día prendado de una hermosa joven entrevista tras una reja de una casa de esa ciudad.

En ciudades de extenso perímetro y en los arrabales más apartados de casi todas ellas, calles y callejones estarían limitados, no sólo por las fachadas de las casas, sino también por altas tapias de huertas y jardines tras cuyas bardas asomaría la copa de algún árbol.

En los.muros de estas casas se abrían puertas pequeñas, más bien 'postigos. Las Ordenanzas medievales de Toledo siguen la tradición musulmana al disponer que "non deue fazer ninguno puerta de su casa delante puerta de su vezino... Ni otrosí en las tiendas, ni las alfondegas, ni los baños..., non se deuen fazer las puertas fronteras, ca es gran descubrición."

La puerta exterior daba paso a un zaguán desde el que, por otra puertecilla, descentrada respecto a la primera para que no fuese posible apercibir el interior de la vivienda desde de la calle, se penetraba en ella. "Las puertas de la calle-decía Martínez Mazas de las de las casas de Jaén-tienen todavía dinteles de madera, aunque sea la fachada de piedra, y como estaban casi siempre cerradas por el genio oscuro y receloso de los moros, sólo se entraba por un postigo bajo y estrecho, a manera de puerta de castillo, de manera que apenas cabe un hombre encorvado".

\section{De las calles de las ciudades hispanomusulmanas \\ a las del Renacimiento.}

Hasta el siglo XVI las ciudades hispanomusulmanas conservaron casi totalmente su antigua fisonomía. Después de su conquista, expulsados los moros o trasladados a los arrabales extramuros cuando permanecieron en ellas, sus viviendas pasaron a serlo de los conquistadores. Estos debieron limitarse a abrir y a ensanchar huecos en los muros exteriores.

Los baños siguieron abiertos, destinados la mayor parte de la semana al uso de los cristianos y tan sólo un día al de los musulmanes y otro al de los judíos. En las tiendecitas de la alcaicería y en los diversos zocos continuaron vendiéndose los mismos productos. Los judíos, igualmente odiados por cristianos y musulmanes, siguieron habitando sus barrios y asistiendo los sábados a las sinagogas. Las mezquitas consagráronse para el culto cristiano, aunque no transcurrió mucho tiempo antes de que la mayoría de los antiguos ora- 
torios islámicos, casi todos edificios pobres y frágiles, fueran sustituídos por templos abovedados de gran elevación, conforme a las necesidades del culto y a los gustos de los conquistadores. A la voz del almuédano entonando cinco veces durante la jornada sus melancólicas llamadas a la oración, sucedió, en los mismos alminares en los primeros tiempos, el ronco tañido de las campanas, cuyos sones tanto indignaban a los musulmanes devotos. Alguna transformación hubo en el interior de los recintos murados al fundarse numerosos y vastos conventos, enriquecidos con cuantiosas donaciones. Sus iglesias se hicieron de nueva planta; pero los edificios de vida monástica fueron con frecuencia resultado de encerrar dentro de altas tapias casas, palacios y calles, formándose así enormes e irregulares manzanas que amenazaban absorber el recinto murado. Tan rápido fué su crecimiento, que repetidamente se dictaron disposiciones para contenerle, como las de Toledo a raíz de la conquista y las del rey don Pedro IV en 1370 mandando que los monasterios e iglesias existentes no aumentaran sus áreas ni se edificase ninguno măs, pues su número y extensión dificultaban el desarrollo del caserío y de los habitantes. Permanecieron en las ciudades reconquistadas por los cristianos las murallas, tras cuyas almenas tan sólo asomaban antes finos alminares, encerrando un apretado caserío de poca altura. Pasados unos cuantos años comenzaron a sobresalir por encima de la cerca los grandes muros de los nuevos templos, a cuyo lado se levantaban altas torres, abiertas en su parte superior por arcos para las campianas. Pero, a pesar de estas transformaciones, lias líneas generales del trazado urbano siguieron siendo las de la ciudad islámica.

En la segunda mitad del siglo XV difundióse por la Península, en un anticipo del Renacimiento, la moda de los desfiles suntuosos, de las justas y los torneos, de los juegos de cañas y del correr de toros y sortijas como espectáculos urbanos. Cuando en las ciudades musulmanas se celebraba un festejo parecido, faltas de espacios libres en su recinto cerrado, tenían lugar extramuros. Así los actos públicos en Córdoba, como las revistas de tropas, verificábanse en la Mosala o Xarea, campo abierto en las afueras, y en la Granada nazari en la Tabla de la Sabika de la Alhambra. en el exterior del recinto. Pero ahora se querían celebrar fiestas públicas en un escenario urbano $\mathrm{y}$ para ello hubo que crear nuevas plazas o ensanchar y reformar las antiguas, rodeándolas de casas de varias plantas cuyas fachadas se abrían por numerosos balcones y miradores. En Granada, por ejemplo, en 1505 dió el rey licencia para hacer la plaza Nueva, y a los 72 nueve años determainóse formarla, cubriendo el río Darro en exten- 
sión de 72 metros. En 1513 acordó el Ayuntamiento de la misma ciudad poblar el campo de Abulnest, hoy del Príncipe, haciendo "una plaza muy honrada para fiestas de justas y toros". El mismo año expidió una cédula el rey don Fernando, en nombre de su hija, ordenando comprar casas para ensanchar la plaza granadina de Bibarrambla, lo que se llevó a cabo de 1516 a 1519. El magnífico condestable don Miguel Lucas de Iranzo, de 1460 a 1473 y én una población no muy importante como Jaén, fué "comprando y acrecentando anchuras y exidos y plazas"; era la época de las fiestas y juegos que ese gran señor, de humilde origen, gustaba prodigar y que terminaron con su oscuro asesinato ante el altar de la iglesia mayor de Jaén.

Al mismo tiempo empezaron a rodar por los caminos y calles de nuestra Patria los primeros coches, traídos, según se dice, por Margarita de Austria en 1497.

En el siglo XVI, al triunfar plenamente el Renacimiento, comienzan las gentes a pedir regularidad y ordenaciones y simetrías, no sólo en los edificios, sino también en los conjuntos urbanos. Hay un gran deseo de vastos espacios libres, de amplias perspectivas, de trazados rectilíneos, de jardines y paseos con fuentes monumentales, de construcciones aisladas que puedan contemplarse desde todas las direcciones. Ya los Reyes Católicos quisieron que las ciudades tuvieran edificios suntuosos, considerando cuánto "se ennoblecen con tener casas grandes y bien fechas", y ordenaron, el año 1480, que todas las ciudades y villas de Castilla y sus señoríos que carecieran de casa consistorial para celebrar sus ayuntamientos y consejos edificasen una inmediatamente, bajo pena, en caso de no hacerlo, de perder sus oficios los regidores y justicias.

Las nuevas viviendas, casas y palacios se abrieron cada vez más al exterior. Al recato, a la desnudez por fuera, al hermetismo misterioso de las viviendas musulmanas, sustituyó el afán de ostentación, manifestado por fachadas ricamente decoradas y con grandes escudos. El centro de las casas de alguna importancia $y$ de los palacios lo ocupó un amplio patio, abierto por grandes puertas al zaguán y a la calle, que viene a ser, por su monumentalidad, como una prolongación de la fachada. Pero en cambio, baños y letrinas, abundantes $\mathrm{y}$ bien dispuestos en las casas hispanomusulmanas, desaparecieron casi por completo, eclipse que durará varios siglos. Triunfa el afán de ostentación, que algunas veces significa ausencia de ser, es decir, vacío interior de la personalidad humana, tras el que asoma el énfasis. Por boca de maese Pedro un egregio español que vivió el tránsito del 
siglo XVI al XVII recordaba el sentido de nuestra tradición medieval, tanto de la castellana como de la musulmana, con las siguientes palabras de admonición dirigidas a Ginés de Pasamonte: "Llaneza, muchacho: no te encumbres; que toda afectación es mala."

Veamos algunos datos sobre las reformas urbanas de. Toledo, Málaga, Granada y Sevilla en el reinado de los Reyes Católicos, cuando la boga de la estética nueva, traída y propagada por los elementos dirigentes de la vida española, coincide con un momento de expansión y riqueza grandes.

Dice una disposición de la reina doña Juana que en bastantes de las calles públicas de Toledo "están edificados muchos edificios saledizos e corredores, e balcones, por las delanteras de las cassas que salen por gran trecho a las dichas calles, e toman' e ocupan toda o la mayor parte dellas, de manera que las dichas calles están muy tristes y sombrías de manera que en ellas no puede entrar ni entra claridad, ni sol, e de contino están muy húmedas e lodosas e suzias", en vista de lo cual dispuso que en adelante "no fagan, ni labren, ni edifiquen en las calles públicas de la dicha ciudad, ni en alguna dellas, pasadizos, ni saledizos, corredores, ni balcones, ni otros edificios algunos que salgan a la dicha calle fuera de la pared en que estuuiere el tal edificio; ...por manera que las dichas calles públicas queden exentas y sin embarazo de ningún pasadizo, ni saledizo, ni otro edificio alguno de los sobredichos, y estén alegres y limpias e claras, y puedan entrar y entre por ellas sol y claridad".

La misma ciudad de Toledo aún en 1525, cuando la visitó Andrea Navajero, tenía "muchas casas buenas y cómodos palacios, más quizá que ninguna otra ciudad de España, pero no tienen por fuera vista ni apariencia alguna. Son todos hechos de cantos, y alguna parte de piedra labrada y de ladrillo y lo demás de tierra, como se usa en España; tienen pocos balcones y pequeños, lo cual dicen que es por el calor y por el frío, y la mayor parte de las casas no tienen más luz que la de la puerta".

En una real cédula de los Reyes Católicos de 1501, en la que se señalan las calles de Málaga que habían de ocupar los diferentes oficios, ya se alude al derribo de los ajimeces: "debíamos mandar que en las plaças e calles donde se Reparten los dichos ofiçios se quitasen los aximezes de las dichas calles e de las otras calles prinçipales de la dicha cibdat".

Münzer cuenta en 1494 que en Granada el rey don Fernando había dispuesto ensanchar muchas calles, derribar algunas casas y hacer mercados; cuatro años después, por ornato, se habían "cortado 
algunos aximezes de moros". En 1502 refiere Antonio de Lalaing, señor de Montigny, que los Reyes Católicos hicieron derribar varias calles pequeñas de Granada, mandándolas hacer anchas y grandes y obligando a los habitantes a construir casas vastas, a manera de las de España. Desde 1501 se dieron repetidas órdenes, en la misma ciudad; para derribar los "aximezes y balcones", por ser las calles en muchos sitios angostas; toda persona que "labrase pared que saliese a las calles o plazas" debería meterse "con la pared de como antes estaba un asta de ladrillo en su casa, o más, o menos, según pareciese a las personas" nombradas para ello. Las Ordenanzas se refieren a "enderezar las calles", con prohibición de hacer "ajimez, o portal ni pasadizo... fuera de la haz de su propia pared, en las calles o plazas", y de "adobar, ni reparar ninguna ajimez, ni cobertizo sin licencia de la ciudad".

Hasta los comienzos del siglo XVI conservó Sevilla su estructura medieval. En esa centuria fueron derribadas, entre otras varias, las callejas de Ios costados de la Catedral y parte de las de las murallas del Alcázar.

El ilustre caballero sevillano Pedro Mexia en sus Coloquios o diálogos, editados en 1548, escribe que en su ciudad natal "casi en nuestros tiempos se quitaron los ajimezes o salidizos, porque hacían las calles sombrías y húmedas" y que desde hacía diez años todos labraban "ya a la calle", habiéndose hecho "más ventanas y rejas a ella que 'en los treinta de antes". Elogia también las nuevas "delanteras" de las casas. Alonso Morgado, en su Historia de Serilla, publicada en 1587, repite lo mismo, añadiendo que "en tiempos pasados todo el edificar era dentro del cuerpo de las casas, sin curar de lo exterior; según que hallaron a Sevilla de tiempo de Moros. Mas ya en éste hacen entretenimiento de autoridad, tanto ventanaje con rejas, y celosías de mil maneras, que salen a la calle, por las infinitas damas nobles, y castas, que las honran y autorizan con su graciosa presencia". Durante todo el siglo XVI no dejaron de derribarse en Sevilla los ajimeces o "salidizos" que hacían a las calles húmedas y sombrías y, por consiguiente, poco saludables. Con exceIente sentido, Pedro Mexia pondera los edificios bajos, humildes $y$. de poca autoridad, por su escasa altura, que no parecían bien a las gentes llegadas de ciudades en las que había entonces casas de tres y cuatro altos, como Barcelona. Aconseja que, para cumplir con la hermosura y el ornato, no se hicieran más altas, pues en un clima cle calurosa humedad como el de Sevilla es necesario que lo princi- 
pal de las casas sea bien visitado por el sol y el aire y pueda éste. renovarse fácilmente.

Todas estas disposiciones del siglo XVI respecto a derribo de ajimezes y reducción de aleros nos han privado de obras de carpintería hispanomusulmana y mudéjar que en algunas ciudades, como Toledo, serían magníficas, si juzgamos por los escasos restos conservados en easas apartadas y en viejos conventos, restos que en estos últimos años han sido arrancados de sus emplazamientos primitivos para pasar a manos de los chamarileros.

\section{Concepto de la calle.}

La separación y el aislamiento de los arrabales, de los barrios y aún de las calles; la angostura y tortuosidad de éstas últimas; los pasadizos y los muros y puertas de cerramiento, satisfacían en las ciudades hispanomusulmanas a una necesidad primordial de defensa. En períodos frecuentes de inseguridad y revueltas, si la cerca exterior protegía contra el enemigo lejano, todos esos otros obstáculos eran necesarios para defenderse del interior, más peligruso por más próximo. De Córdoba cuenta un cronista que antes del último cuarto del siglo $X$, sus 'vecinos se veían obligados a velar la noche entera para guardarse de las acometidas de los malhechores, que encontraban amparo y protección hasta en la misma corte. $\mathrm{Y}$ en el siglo XII, refiere Ibn Said, abundaban los asesinatos y los robos en la antigua capital del califato, cuyo populacho estaba reputado tradicionalmente por su carencia de escrúpulos y su tendencia a criticarlo todo y a estar siempre descontento. Los veciros, para disfrutar de una relativa tranquilidad, necesitaban vivir apretados codo con codo. En las frecuentes revoluciones populares y en época de anarquía era así fácil a unos cuantos hombres defender el acceso al callejón en el que se abrían las puertas de sus hogares.

Pero, además de esa primordial necesidad defensiva, el trazado de las calles traducía el concepto que de la vida urbana tenían sus habitantes, totalmente distinto al de los de las cristianas. Para las gentes de Occidente que habitan en un clima benigno, las calles de los barrios populares son como prolongación ruidosa de las propias viviendas; a ellas concurren con frecuencia los vecinos de las casas inmediatas para disfrutar del sol y del aire y charlar. En las fachadas se abren numerosos huecos de regular tamaño, a los que suelen asomarse los vecinos que desean gozar del espectáculo urbano.

Los ciudadanos hispanomusulmanes acudían a sus actos de de- 
voción y a sus quehaceres comerciales o industriales a la parte central, ruidosa y frecuentada, de la ciudad, donde estaban la mezquita mayor, la alcaicería, las calles llenas de tiendecitas y la mayoría de los zocos; pero sus viviendas se abrían generalmente en el fondo de callejones apartados, solitarios y silenciosos, en los que el poco tránsito permitía crecer la hierba. Tras algún ajimez, las mujeres podían contemplar la calle a cubierto de miradas indiscretas, pero el sitio de expansión de ellas y de los niños era el terrado, en las ciudades mediterráneas, o la algorfa (sobrado) o galería alta, cuando la casa se cubría con tejado. Desde esos lugares la vista podía recrearse, más que en la contemplación de los espectáculos callejeros, en la visión de las montañas lejanas, sirviendo de fondo a la vega, y de los alminares próximos.

Para algunos de los habitantes de nuestras ruidosas e incómodas viviendas burguesas, obligados al contacto continuo con sus convecinos, parecerá un ideal inasequible el de vivir en una casita situada en el fondo de un estrecho callejón de una ciudad populosa, en la que se disfrutaría, a la vez que de las ventajas y comodidades de una gran urbe, de la soledad y de aquel "mudo y sosegado silencio" que, como don maravilloso, tantas veces pondera Cervantes.

Los urbanistas modernos propugnan la división de la ciudad en sectores bien definidos, destinados a vivienda, vida oficial, industria, comercio, etc. El sistema, como se ha visto, no es invención reciente. Ya se había llevado a la práctica de una manera natural y perfecta, como consecuencia de una evolución biológica y no de una brusca imposición técnica, en las ciudades hispanomusulmanas, cuyos diferentes sectores formaban un organismo perfectamente trabado, en el que el tránsito de unos a otros tenía lugar de forma insensible, sin solución de continuidad.

Tal vez algún día nuestros futuros urbanistas reanuden la tradición interrumpida hace cinco siglos y tracen o reformen las ciudades de forma que, al mismo tiempo que las calles ruidosas de intenso tráfico, obligadas por la vida moderna, haya otras apartadas, de viviendas, en las que sólo resuenen, de tarde en tarde, los pasos de unas pocas gentes.

Se habrá logrado así asociar felizmente la vida campesina, con su tranquila monotonía, a la febril y brillante de los grandes centros urbanos.

\section{Ambiente y movimiento callejeros.}

Para dar animación a este frío esquema de escenario urbano ha- 
bría que evocar el movimiento y la vida que tuvieran las calles de las ciudades hispanomusulmanas en la época medieval. Quede para otros labor tan ardua y sugestiva. Señalaré tan sólo unos cuantos rasgos que permitan imaginar, en sus líneas generales, el ambiente de esas villas y ciudades antes de su paso a manos de los conquistadores cristianos.

Desde su casa, situada en el fondo de estrecha y silenciosa callejuela, un vecino de Córdoba, Sevilla, Granada, Ronda, Málaga o Almería, se encamina hacia el centro de la ciudad. Cruzando calles angostas y poco concurridas, cortadas por arcos y encubiertas a trechos por pasadizos altos que producen violentos contrastes de luz y sombra, llegaría a las inmediaciones de la mezquita mayor. En torno de ésta se hallaban la alcaicería, las alhóndigas y los zocos más concurridos y las calles en las que artesanos y comerciantes se agrupaban por oficios o identidad de mercancías en venta. Ocupaban los últimos tiendecitas bajas y estrechas; con nichos o alacenas, en las que apenas podían mantenerse en pie. Acurrucados y quietos el día entero, no necesitaban levantarse para coger cualquier objeto y presentarlo al comprador. Tablas móviles, que al bajarse rebasaban algo del muro de fachada, servían de mostradores, y otras en lo alto. inclinadas, a modo de tejadillos, protegían del sol y de la lluvia al vendedor y a su mercancía.

Nuestro vecino había pasado de la tranquilidad y el silencio de su calle al apretujamiento y barullo de las céntricas, extremados los viernes, cuando era obligado para todo buen musulmán acudir a la plegaria a la mezquita mayor. A fines del siglo XII, bajo el dominio almohade, se amontonaban los fieles en torno de la vieja de Sevilla, al no caber en su interior ni en el patio y galerías, mezclándose con los transeúntes y vendedores, por lo que hubo de construirse otra más amplia, cuyo alminar fué la torre que hoy llamamos Giralda. "Las calles están ahogadas de gente... En los zocos se apretujan los comercios", decía, refiriéndose a Málaga, Ibn al-Jatib, en el siglo XIV.

El reducido espacio que para la intensa circulación ofrecían las pequeñas plazas y calles del centro de la ciudad quedaba aún más disminuído durante gran parte de las horas del día por los puestos provisionales instalados al aire libre, en plena calle, con mostradores portátiles y toldos o tinglados de suficiente altura para que no pu78 diese tropezar en ellos la cabeza de los jinetes, y por las caballerías 
estacionadas en espera de que sus dueños terminasen sus asuntos o sus deberes religiosos en la mezquita próxima. En torno a la mayor, los poyos situados entre sus contrafuertes, y la plaza inmediata, eran los lugares más solicitados por los vendedores, por más concurridos. Algunos comerciantes aprovechados pretendían reservárselos, pero el almotasen-mubtasib-, que circulaba desde hora temprana, jinete en su caballo, recorriendo zocos y calles seguido de varios guardas, uno de los cuales llevaba una balanza para comprobar el peso del pan, velaba porque los fueran ocupando por orden de llegada: el más madrugador se instalaba en el más propicio para la venta.

Perfumistas y drogueros preparaban sus productos a la vista del público, y era frecuente que, distrayendo la atención de éste mediante el relato de entretenidas anécdotas, los falsificasen, a pesar de la vigilancia del almotacen, perseguidor de toda clase de fraudes y latrocinios comerciales, desde los elementales de menguar el peso de las mercancías vendidas, hasta los más complicados e ingeniosos de los perfumistas. Entonces, como hoy y como siempre, el comerciante juzgaba escasa toda ganancia.

Prohibíase situarse cerca de la mezquita mayor a los vendedores que podían manchar el suelo con sus mercancías, como eran los de aceite, aves y conejos, así como-dejar las bestias, por la misma razón, cerca de sus puertas, sobre todo poco antes del mediodía del viernes, cuando tenía lugar la oración colectiva. Ese mismo día, por la mañana, los vendedores barrían cuidadosamente la entrada al oratorio y sus inmediaciones.

Una muchedumbre abigarrada y pintoresca circulaba por el centro de la ciudad: hispanomusulmanes, mozárabes, judíos, árabes de Oriente, bereberes, catalanes y cristianos del Norte, francos, genoveses, eslavos, cada cual con su vestimenta diferente y expresándose en distinta lengua. Vendedores ambulantes, compradores, paseantes ociosos, mendigos importunos que iban a estacionarse sobre todo a las puertas de baños y mezquitas, llenaban las calles próximas al oratorio mayor, en unión de un crecido número de campesinos que acudían de las alquerías y pueblos próximos a vender sus productos o a adquirir los de los artesanos de la ciudad. El peatón circulaba apretujado por la muchedumbre, hostigado por los mendigos, tropezando con el saliente de los mostradores, teniendo que apartarse a cada momento para dejar paso libre a jinetes, caballerías de carga, matarifes, que llevaban a las carnicerías, sobre los hombros, las reses muertas, y a los que porteaban en angarillas los materiales de 
construcción. El incesante fluir de la muchedumbre producía fuerte bullicio, mezcla de voces y conversaciones, de los gritos de los pregoneros públicos, que anunciaban la venta en subasta de esclavos, caballos, verduras o carbón, y de los pregones de los comerciantes ambulantes, ofreciendo a gritos su mercancía. A estos ruidos uníanse las voces de los que se ganaban la vida relatando historias y de los adivinos que decían la buena ventura. De tiempo en tiempo-cinco veces al día-, los almuédanos dejaban caer sobre la ciudad, desde la terraza de los alminares, sus llamadas melancólicas convocando a los fieles a la oración.

Una vez resueltos sus asuntos en el centro urbano, nuestro vecino desandaba el camino, de vuelta a su hogar. A medida que se iba apartando del centro, percibía cada vez más lejana la algarabía descrita. Al traspasar la puerta de su casa, penetraba en el mundo maravilloso del silencio.

Sentado entonces en el terrado o en la algorta-gurfa-, podía contemplar la vega y las montañas que azuleaban en la lejanía, gozando de la serenidad de las últimas horas de la tarde, y, si su espíritu era inclinado a la meditación sobre el incierto destino humano, reflexionar acerca de lo precario de toda esa agitada vida urbana, ya que una revuelta, la guerra, la sequía, una inundación o una epidemia podían en pocas horas arruinar la ciudad y dejär desiertos zocos y calles. Aún en el fondo de su vivienda, tras las puertas del barrio, de la calleja y de la casa, le acechaba constantemente la amenaza de la ruina y de la muerte. Ante la inseguridad de su vida tal vez pensase en que ni aún los poderosos de la tierra la lograban más tranquila y feliz, recordando cómo, al morir el gran Abd ab-Rahman III, después de un dilatado y glorioso reinado de cincuenta años, siete meses y tres días, se encontró una lista escrita de su mano en la que figuraban por orden cronológico los días de su existencia en los que había disfrutado de una alegría serena, sin mezcla de preocupación alguna. Figuraban en ella catorce.

Leopoldo Torres Balbas

Catedrático de la Escuela Superior de Arquitectura. 